\title{
Analysis and Design of RF Filters with Lumped and Distributed Elements
}

\author{
G.T.Bharathy, S.Bhavanisankari, T.Tamilselvi, G.Bhargavi
}

\begin{abstract}
Radio frequency (RF) and microwave filters characterize a class of electronic filter, intended to function on signals in the frequency range between megahertz to gigahertz. A Lumped element $R F$ filters is a passive device whose size across any dimension is much smaller than the operating wavelength so that there is minimal change in phase of waveform between the input and output connections. RF filters can also be designed using distributed elements in which all the inductors and the capacitors are replaced by the open and short circuit stubs. This paper concentrates on an analysis and design of low pass filter with the help of only lumped elements and a high pass filter with both lumped and distributed elements.
\end{abstract}

Index Terms: Lumped elements, RF filters, LC components, stubs, Advanced Design System (ADS).

\section{INTRODUCTION}

RF filters allow or prevent selected signals or frequency in order to eliminate the noise or pass through of unwanted signals. Major classifications of filters are based on whether it is digital or analog, passive or active, non-linear or inear, time invariant or variant, non-causal or causal. The filters may be active and passive. Butterworth, Chebyshev, Bessel and Elliptical are some of the types of active filters. An active filter is a type of analog circuits, in which electronic filter are implemented using active components classically an amplifier. The predictability, performance and cost of a filter is improved by the inclusion of amplifiers. Passive implementation of linear filter are based on the combination of resistor, inductor and capacitor. These are jointly identified as passive filters. Such filters does not need peripheral power supply and it doesn't comprise of active mechanisms such as diodes.

\section{RF FILTERS}

There are four types of filters that can reject and allows signals in a dissimilar way, by means of the accurate choice of RF filters it is likely to permit required signals and reject those that are undesired. The basic categories of RF filters are:

G.T.Bharathy, Electronics and Communication Engineering, Jerusalem College of Engineering, Chennai, India.

S.Bhavanisankari, Electronics and Communication Engineering, Jerusalem College of Engineering, Chennai, India.

T.Tamilselvi, Electronics and Communication Engineering, Jerusalem College of Engineering, Chennai, India.

G.Bhargavi, Electronics and Communication Engineering, Jerusalem College of Engineering, Chennai, India.

\section{A. Low Pass Filter:}

It discards all frequencies lower than a definite frequency point and allows signals to pass beyond that threshold.

\section{B. High Pass Filter:}

The high pass filter can allow above a certain frequency point while all lower frequency are attenuated (rejected).

\section{ACTIVE AND PASSIVE FILTERS}

\section{A. Active Filters:}

- An active filter is a analog circuit used to implement an electronic filter with the help of active components.

- Amplifiers incorporated in a filter design can be utilized to improve

$$
\begin{aligned}
& >\text { Cost } \\
& >\text { Performance } \\
& >\text { Predictability of a filter }
\end{aligned}
$$

1) Butterworth: It promises a flat response in the pass band and an ample roll-off. It approximates the faultless filter fit in the pass band. This kind of filter is superior and uncomplicated to realize. It also admirable for audio processing applications.

2) Chebyshev:Chebyshev filters are digital or analog filters have steeper roll-off and added passband ripple or stopband ripple compared to butterworth filters. It is prominent in RF filter-using inductor and capacitor i,e. LC arrangement which offers the speedy transition from passband to stopband. chebyshev filter is extensively used in application of RF filters in which ripple may not be a problem. chebyshev filter basics are roll-off, ripple, cut-off frequency.

\section{B. Passive Filters:}

Implementation of passive linear filters are based on the combinations of resistor(R), capacitors(C) and inductor(L).They do not depend upon an peripheral power supply, so it is called as passive filters and they do not include active components such as transistors. simple passive filters are single element they contain only one reactive

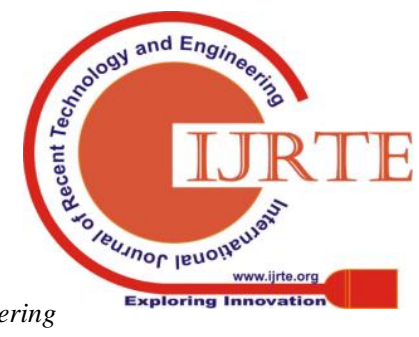




\section{Analysis and Design of RF Filters with Lumped and Distributed Elements}

component either $\mathrm{L}$ or $\mathrm{C}$. More complex filters containing more reactive elements are also available.

\section{RF FILTER DESIGN \& SCALING}

The normalized form of filter is realized initially and then the transformation is required.

$$
\begin{gathered}
C=\frac{C_{n}}{2 \pi f_{c} R} \\
L=\frac{R L_{n}}{2 \pi f_{c}}
\end{gathered}
$$

\section{Where:}

$\mathrm{C}=$ real value of the capacitor

$\mathrm{L}=$ real value of the inductor

$\mathrm{Cn}=$ normalised capacitor value

$\mathrm{Ln}=$ normalised inductor value

$\mathrm{R}=$ load resistor value

$\mathrm{fc}=$ cut-off frequency

\section{SIMULATION RESULTS}

\section{A. Low Pass Filter:}

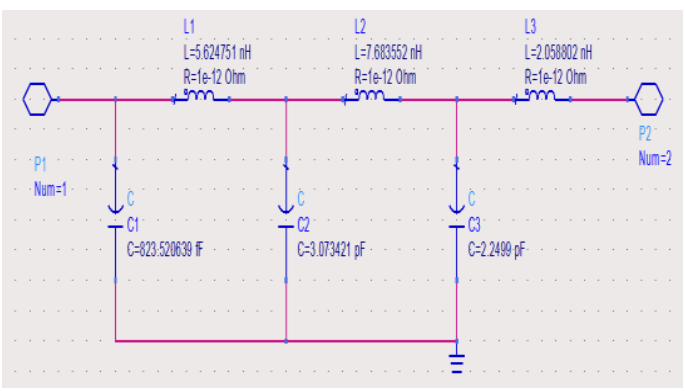

Fig.1 LC Circuit of Low Pass Filter

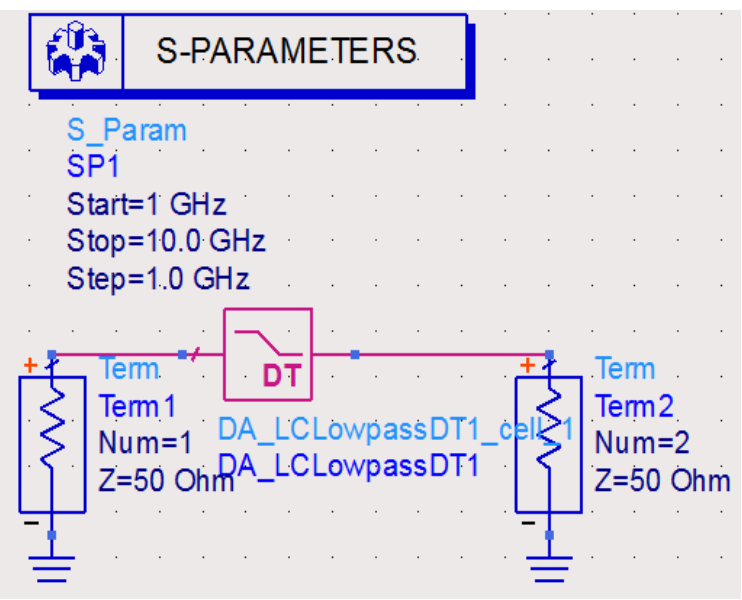

Fig. 2 Block Diagram of Low Pass Filter

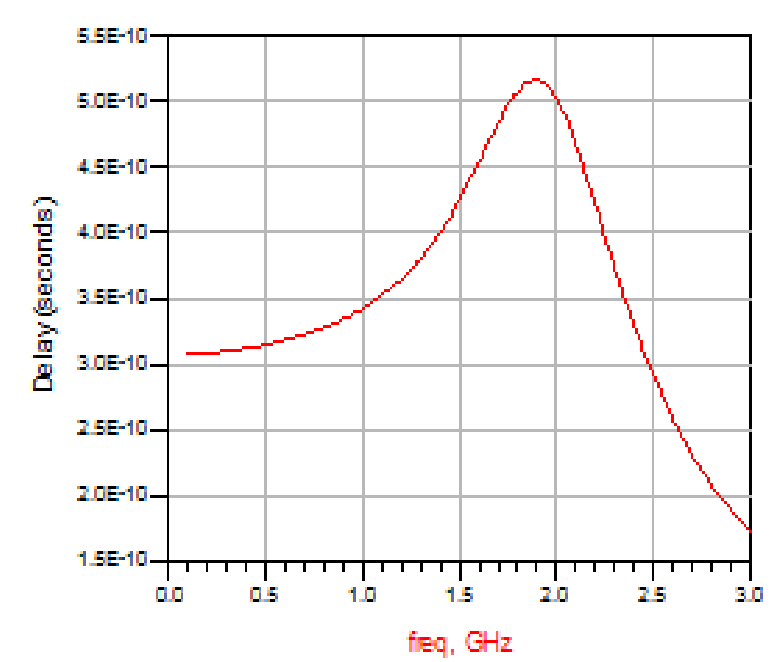

Fig. 4 Delay Response of Low Pass Filter

\begin{tabular}{|c|c|c|c|c|}
\hline \multirow[b]{2}{*}{ Input Parmeters } & $F_{p}$ & $F_{5}$ & $\mathrm{AP}$ & As \\
\hline & $2000 E 9$ & $3.000 E 9$ & 3.000 & 20.000 \\
\hline \multirow{3}{*}{ Peformance } & PB Edge & SB Edge & Gain Dev $(B B)$ & Delay Dev (ns) \\
\hline & $2.000 \mathrm{GHz}$ & $2.940 \mathrm{GHz}$ & 3.000 & 0.209 \\
\hline & $\mathrm{F}$ & $S 11(A B)$ & $521(0 B)$ & Delay (ns) \\
\hline Marker M1 & $1.26 G-2$ & -24.12 & -002 & 037 \\
\hline Marker M2 & $1.98 \mathrm{Grz}$ & 329 & 273 & 0.51 \\
\hline
\end{tabular}

Fig. 3 Frequency Response of Low Pass Filter 

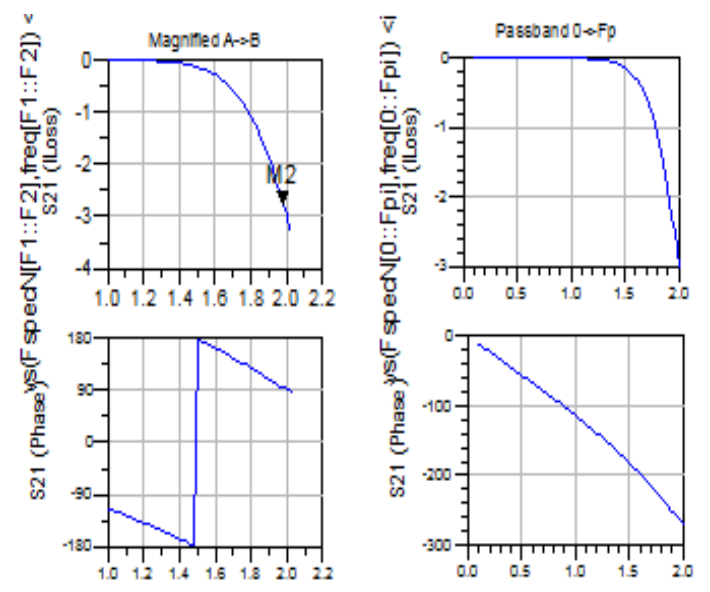

Fig.5 Magnitude and Phase Response of Low Pass Filter

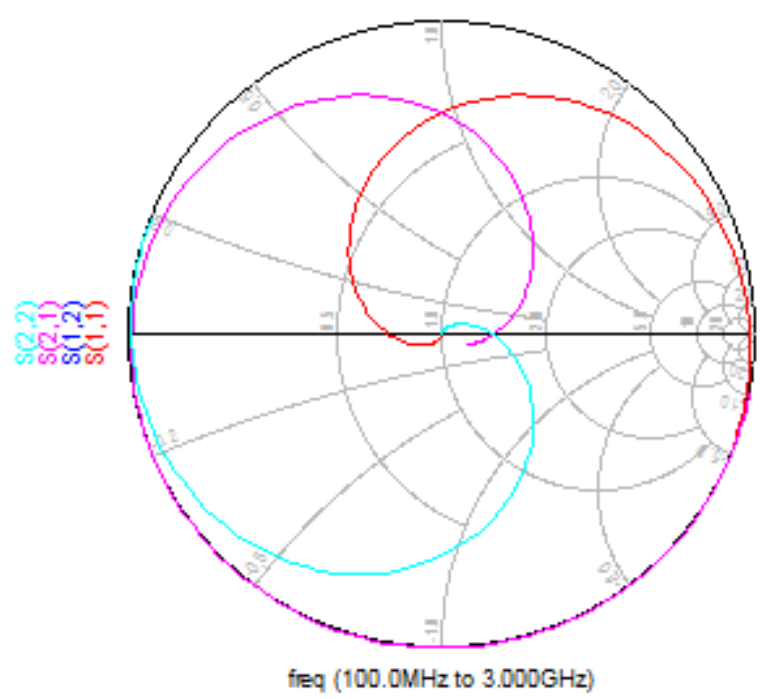

Fig. 6 S Parameters of Low Pass Filter

\section{B. High Pass Filter:}

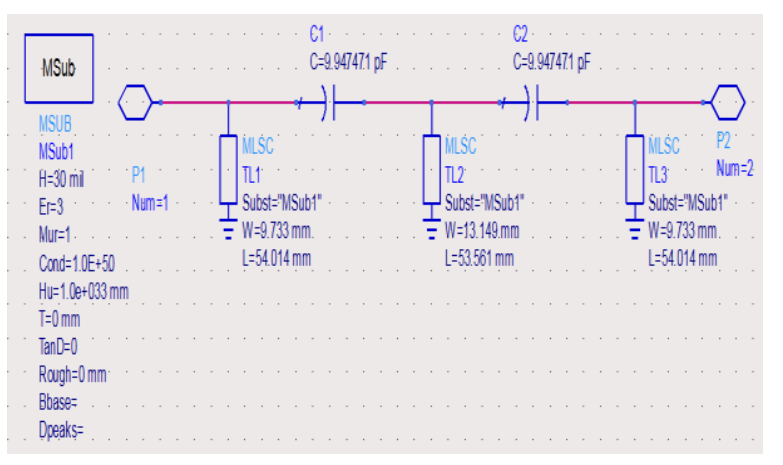

Fig.7 High Pass Filter with lumped and distributed elements

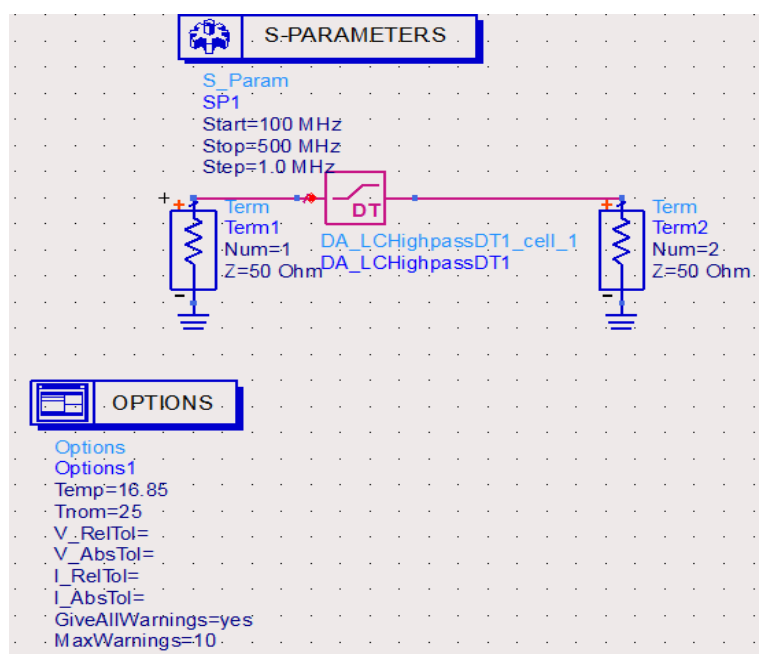

Fig.8 Block diagram of High Pass Filter

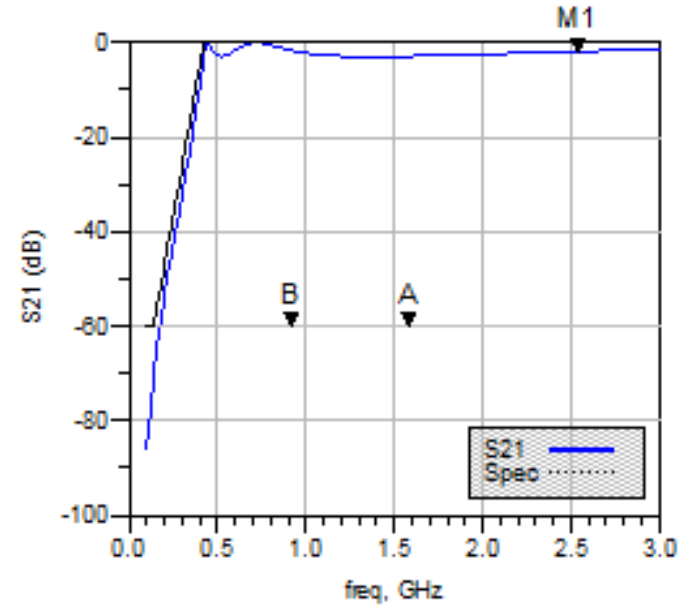

Fig.9 Frequency Response of High Pass Filter

\begin{tabular}{|c|c|c|c|c|}
\hline \multirow[b]{2}{*}{ Input Parameters } & $F_{p}$ & $\mathrm{Fs}$ & $A_{p}$ & As \\
\hline & 4.200E8 & $1.450 \mathrm{OE} 8$ & 3.000 & 60.000 \\
\hline \multirow{3}{*}{ Performance } & PB Edge & SB Edge & Gain Dev $(d B)$ & Delay Devins) \\
\hline & $420.0 \mathrm{MHz}$ & $180.0 \mathrm{MHz}$ & 2.997 & 6.426 \\
\hline & $F$ & $S 11(\mathrm{~dB})$ & $S 21(\mathrm{~dB})$ & Delay (ns) \\
\hline Marker M1 & $254 \mathrm{GHz}$ & 454 & -138 & 004 \\
\hline Marker M/2 & $100 \mathrm{Grz}$ & -392 & -226 & 0.27 \\
\hline
\end{tabular}

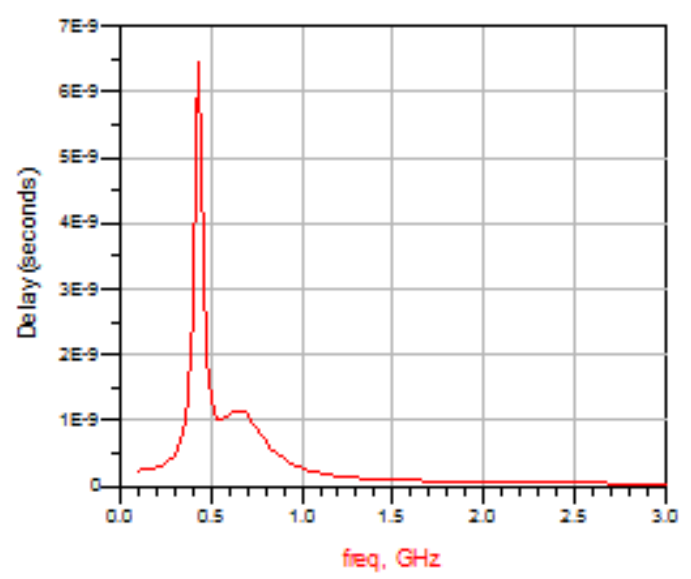

Fig.10 Delay Response of High Pass Filter

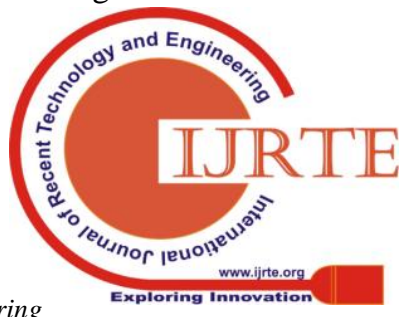

Blue Eyes Intelligence Engineering \& Sciences Publication 


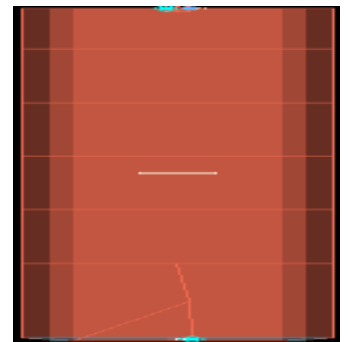

Fig.11 Layout of High Pass Filter
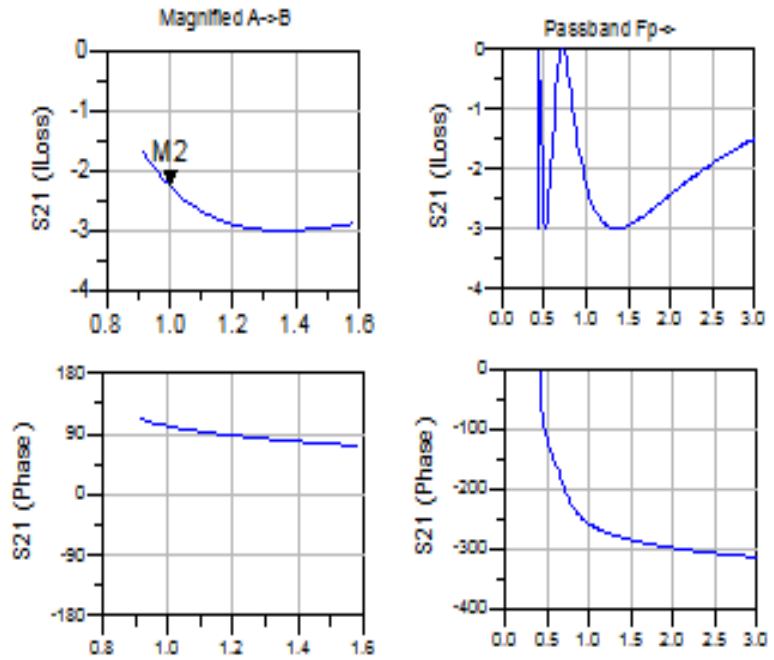

Fig.12 Magnitude and Phase Response of High Pass Filter

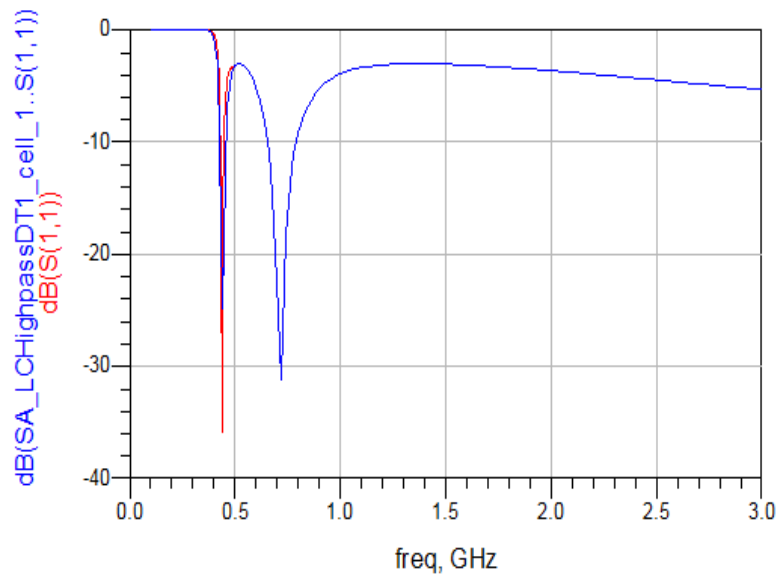

Fig.13 S11 of High Pass Filter

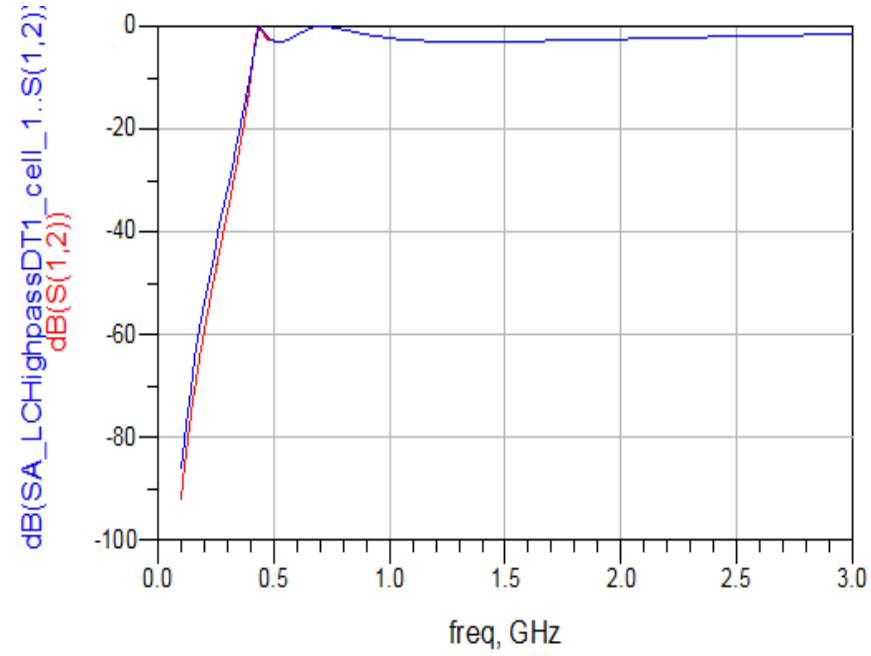

Fig.14 S12 of High Pass Filter

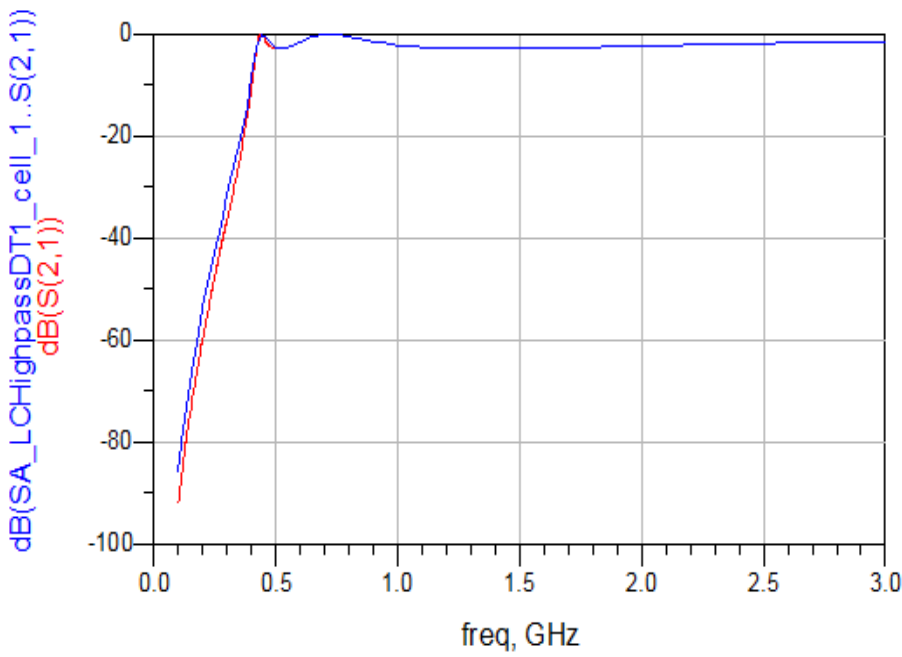

Fig.15 S21 of High Pass Filter

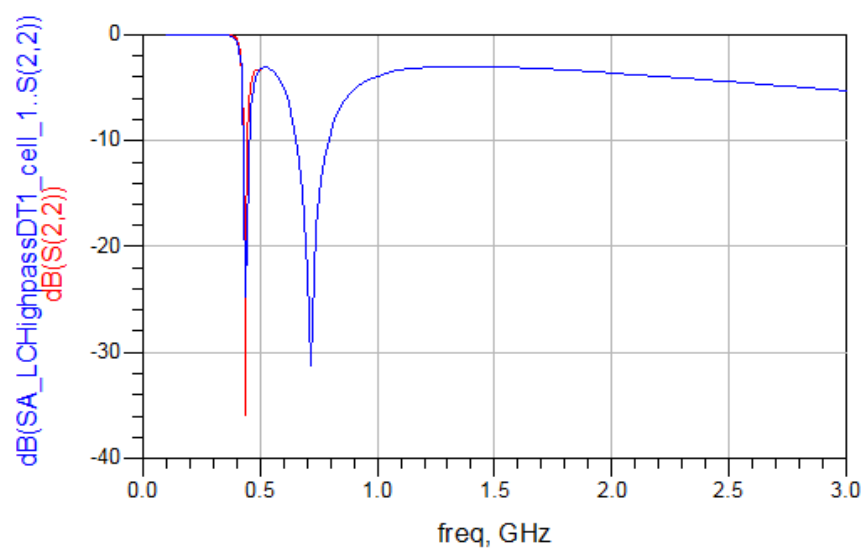

Fig.16 S22 of High Pass Filter

The simulations are implemented using the Advanced Design System software. The simulation results of the low pass filter which is calculated with only lumped elements and the high pass filter designed using the combination of lumped and the distributed elements, shows that the filter perfectly allows the desired frequencies and rejects the undesired frequencies for which it was designed.

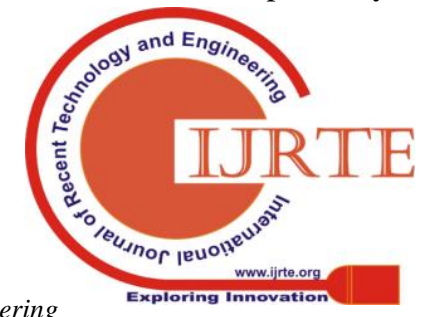

Blue Eyes Intelligence Engineering \& Sciences Publication 


\section{CONCLUSION}

The design, simulation and analysis of the low pass filter that is designed using only lumped elements and the high pass filter designed using the combination lumped and the distributed elements has been done and the simulation results show that the filters are perfectly operating in the designed frequency. The design can be further be implemented and used for the required applications.

\section{REFERENCES}

1. Defu wang,Bjorn Thorsten Thiel and Renato negra,'Reconstruction Lumped-Elements Bandpass Filter Suitable for Lowpass Delta-Sigma RF Transmitters",2014 international workshop on intregrated nonlinear microwave and millimetre-wave

2. Y.-C.Ou and G.Rebeiz,'Lumped-elements fully tunable bandstop filters for cognitive radio application,'IEEE Trans .Microwave Theory Tech,vol.59, no,10,pp.2461-2468,oct 2011

3. Dimitra Psychogion,Roberto Gomez-Garcia and Dimitrios Peroulis,"RF Design of Acoustic-Wav e -Lumped-ElementResonator-(AWLR)-Based Bandpass Filters With Constant In-Band Group Delay",in 2017

4. D.Wang and Negra,"Reconstruction filter suitable for Lowpass delta-sigma rf transmitters,"in 2013 IEEE Radio Wireless Symp,Jan 2013,pp.322-324

5. R. Ludwig. RF and Microwave Engineering, University of San Diego. [Online]Available: www.sandiego.edu/ ekim/e194rfs01/filterek.pdf

6. J. A. G. Malherbe. Microwave Transmission Line Filters. First Edition. Dedham: Artech House, 1979

7. George L. Matthaei, Leo Young, E. M. T. Jones. Microwaves Filters, Impedance-Matching Networks, and Coupling Structures. Reprint of the edition by McGraw-Hill. Dedham: Artech House, 1980.

8. David M. Pozar.Microwave and RF Design ofWireless Systems. First Edition. NewYork: John Wiley \& Sons, 2001.

\section{AUTHORS PROFILE}

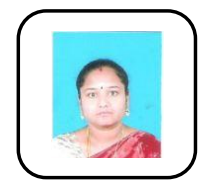

Ms.G.T.Bharathy was born in India in the year 1979 She completed B.E degree in Electronics and Communication Engineering from Easwari Engineering College, Chennai, Madras University, India in the year 2000 and M.E degree in Communication Systems from Shri Venkateshwara College of Engineering, Chennai, Anna University, India in the year 2005. She is now working as Senior Assistant Professor in Jerusalem College of Engineering, Dept. of Electronics and Communication Engineering, Chennai. She is a life member in ISTE. She has worked as Lecturer in the department of ECE in Anand Institute of Higher Technology and Prince Shri Venkateshwara Padmavathi College of Engineering, Chennai. Her research interest is RF and microwave circuits and systems.

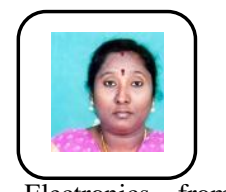

Ms.S.Bhavani Sankari was born in India in the yea 1978. She completed B.E degree in Electronics and Communication Engineering from Thanthai Periyar Government College of Engineering, Madras University, India in the year 1995 and M.E degree in Industrial Electronics from Sri Jeyachamarajendra College of Engineering, Visveswaraya University, India in the year 2003. She is now working as an Associate Professor in Jerusalem College of Engineering, Dept. of Electronics and Communication Engineering, Chennai. She is a life member in ISTE. Her research interest is Communication, Signal Processing.

Ms.T.Tamilselvi was born in India in the year 1978. She completed B.E degree in Electronics and Communication Engineering from Adhiparasakthi Engineering College, Madras University, India in the year 2000 and M.E degree in Embedded System Technologies from College of Engineering, Guindy (CEG Main Campus), Anna University, India in the year 2006. She is now working as Senior Assistant Professor in Jerusalem College of Engineering, Dept. of Electronics and Communication Engineering, Chennai. She is a life member in ISTE. Her research interest is VLSI and Embedded design.

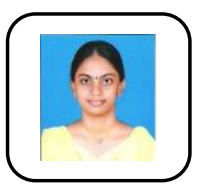

Ms.G.Bhargavi was born in India in the year 1987. She completed B.E degree in Electronics and Communication Engineering from Sri Muthukumaran Institute of Technology, Anna University, India in the year 2009 and M.E degree in Communication Systems from Shri Venkateshwara College of Engineering, Chennai, Anna University, India in the year 2011. She is now working as Assistant Professor in Jerusalem College of Engineering, Dept. of Electronics and Communication Engineering, Chennai. She is a life member in ISTE. Her research interest is Communication Systems. 